Article

\title{
Evaluation and Balance of Cognitive Friction: Evaluation of Product Target Image Form Combining Entropy and Game Theory
}

\author{
Kai Qiu $\left.{ }^{1}{ }^{(}\right)$, Jianning Su ${ }^{1,2, * \mathbb{C}}$, Xinxin Zhang ${ }^{3}$ and Wenjin Yang ${ }^{1}$ \\ 1 School of Mechanical \& Electronical Engineering, Lanzhou University of Technology, \\ Lanzhou 730050, China; 191080203003@lut.edu.cn (K.Q.); 171080203016@lut.edu.cn (W.Y.) \\ 2 School of Design Art, Lanzhou University of Technology, Lanzhou 730050, China \\ 3 School of Architecture and Art Design, Hebei University of Technology, Tianjin 300401, China; \\ y10160052@mail.ecust.edu.cn \\ * Correspondence: sujn@lut.cn
}

Received: 28 July 2020; Accepted: 20 August 2020; Published: 21 August 2020

\begin{abstract}
With the great progress of product development technology, product forms have been greatly enriched by cognitive differences; users and designers have formed a "cognitive friction" phenomenon in the product evaluation process, which results in designers being unable to grasp user emotions accurately and risks of product development failure. This paper aims to balance the cognitive differences between cognitive subjects (users and designers) and evaluates the product image form. First, image entropy is used to evaluate and extract the weight of the product target image. Second, fuzzy Theil entropy is used to evaluate the cognitive friction between cognitive subjects, and its existence and size are visually presented. Then, a cognitive friction balance model is built by combining game theory, the comprehensive evaluation weight between cognitive subjects is obtained, and the product image form is ranked and optimized. Finally, all the research steps are described in the form of a household hair dryer. The results show that fuzzy Theil entropy and game theory have significant advantages in the evaluation and balance of cognitive friction in product design. Thus, the cognitive friction evaluation and balance model constructed from the fuzzy Theil entropy and game theory do not only enable different cognitive subjects to achieve cognitive symmetry, but also screen out product forms that meet the cognitive needs of users. This finding provides the theoretical basis and practical significance for the establishment of a closed-loop model in cognitive friction balance and the reduction of cognitive differences between cognitive subjects in the entire process of product design. It also introduces new ways of thinking and methods for cognitive science research.
\end{abstract}

Keywords: cognitive friction; product image form; fuzzy Theil entropy; game theory; cognitive symmetry

\section{Introduction}

With the great advancement of product development technology, designers and engineers have faced difficulty achieving differentiation in implementing the functional characteristics of products. It is becoming increasingly important to design products that meet user needs and emotional experiences $[1,2]$. With the advancement of technology and interdisciplinary development, artificial intelligence (AI) technology has begun to play an important role in the field of product design. With innovative algorithms and powerful computing capabilities, a large number of design solutions can be generated by computers in a short time, but the reasoning for the user's emotion is still in the exploration stage [3,4]. Most of the extant studies use machine learning technology to learn the actual 
physiological change data to realize the prediction of emotional preference $[5,6]$; however, there is also a large deviation in accurately grasping the distance of emotional preference [7]. Because there is widespread user cognitive information dissipation in the actual evaluation process, users cannot accurately find the solutions they need among a large number of similar solutions after computer screening; thus, the efficiency and quality of product development is seriously affected. However, most designers produce products by using design tools to carry out conceptual plans. They not only focus on a certain stage of the design activity, but also consider the systemic nature of the entire process [8]. Emotion is injected into the entire process of product design, so that the product can be satisfied from the functional level to the user's emotional level [9], and a solution that meets the user's emotional needs can be selected for optimal design and output, which makes it particularly important to accurately grasp the emotional needs of users. Due to the differences in the mental models and professional backgrounds of users and designers, users are significantly different from designers in terms of their understanding, perception, and expression of perceptible product features, which leads to an asymmetry of cognitive information in the process of expressing needs and evaluating products.

In view of the asymmetry of cognitive information, Alan Cooper et al. proposed the concept of cognitive friction (CF) [10] and applied it to the field of product design, to express that the products developed by designers could not fully meet user expectations. This phenomenon might cause confusion for users when using the product [11]. From Alan Cooper, we know that the concept of CF involves three parts: the designer, product, and user. Among them, the product is a cognitive object, and the user and designer are cognitive subjects. In the final analysis, the generation of $\mathrm{CF}$ is caused by the cognitive difference between designers and users. Therefore, visually displaying and balancing $\mathrm{CF}$ is an important way in which to solve the cognitive difference between designers and users, which will also provide a certain theoretical basis for AI to accurately grasp users' emotions.

In current researches, in order to reduce the CF between the designer and the user and establish the correspondence between the cognitive subject's emotions and design features, complex psychological methods and models have been used by researchers. However, the existence of CF and the methods to reduce its influence were only discussed at the perceptual level, the CF was not evaluated quantitatively, and the mechanism of its generation was not discussed. All of these researches, as a result, did not solve the CF fundamentally. Product design and development still have the risk of failure due to the CF between cognitive subjects. Therefore, the quantitative evaluation and balance of CF between cognitive subjects is one of the key factors to determine the success of product development. The paper focuses on how to accurately evaluate and balance the CF between cognitive subjects to achieve the purpose of solving cognitive asymmetry. Because Kansei engineering (KE) has developed various methods for the correlation analysis of product design elements and the emotions of cognitive subjects to identify the relationship between emotional cognition and product design [12], the evaluation of CF is performed via KE and entropy theory. The evaluation of a household hair dryer is taken as an example to complete the research. First, through the collection of product sample cases and the selection of corresponding emotional vocabulary, the evaluation construction of cognitive subjects is completed. Then, based on image entropy and fuzzy Theil entropy, a CF evaluation model is established to explore the existence and size of CF by using a combination of qualitative and quantitative methods. Finally, the CF balance model, combined with game theory, is constructed to complete the optimization of the product image form based on cognitive balance.

We organize the rest of the paper as follows. Section 2 presents the related research (including perceptual engineering, image entropy and fuzzy Theil entropy, and game theory). Section 3 introduces the construction of the CF evaluation model and balance model. Section 4 conducts case studies and presents and verifies the results. Section 5 discusses the entire process, results, and significance of this paper. Finally, Section 6 provides the conclusions of this paper and recommendations for future work. 


\section{Related Studies}

\subsection{Kansei Engineering}

KE $[13,14]$ was proposed by Mitsuo Nagamachi in 1970 and is a technology that associates users' psychological perception with product design elements [15,16]. Designers can obtain the user's perceived image quickly to complete the product design that meets the user's emotional needs through KE methods [17-19]. The general process, as shown in Figure 1, is mainly divided into three steps: image acquisition, model building, and form optimization design. First, to achieve the purpose of image acquisition, a product case set and an image vocabulary set are established by collecting product samples and describing perceptual vocabulary to evaluate the product form, color, material, etc., and to obtain the user's perception [20-22]. Commonly used methods include the semantic difference (SD) method [23], physiological signal experiment method [24], natural language processing [25], and factor analysis [26]. Then, to establish the correlation between perceptual evaluation and design elements, common methods include quantitative theory I [27], rough set theory [28], optimal ideal solution ranking [29], and support vector machines [30]. Finally, researchers use intelligent algorithms to train and optimize models to guide subsequent design. These methods include deep learning [31], swarm intelligence algorithms [32], genetic algorithms [33], and a combination of multiple optimization methods [34,35].

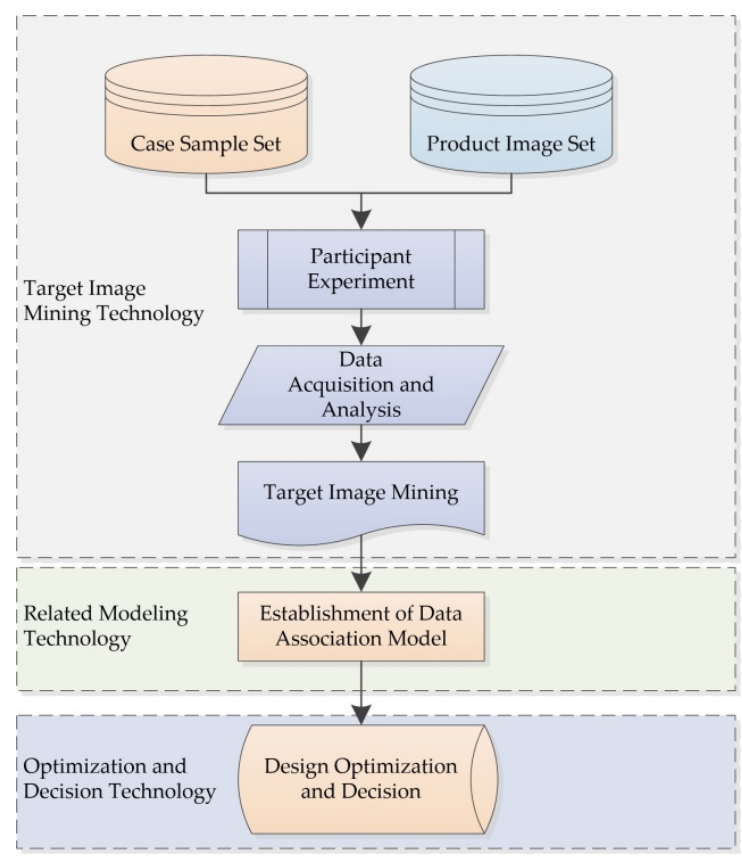

Figure 1. General flow of KE research.

Therefore, the KE method is used to collect case samples and image vocabulary to form an initial sample set and an initial image set in this paper. Then, the target sample set is established through the similarity evaluation, and the target image is evaluated by combining the SD method and the image entropy algorithm.

\subsection{Cognitive Friction}

Friction, as a definition in physics, emphasizes that there is a mutual obstruction between relative motion or two objects that have a tendency toward relative motion. CF is due to the resistance caused by the "grey box" or "black box" of the product to users. CF exists in many aspects. As shown in Figure 2, this resistance arises from the cognitive asymmetry between the user and designer in product design, which causes the user's cognitive discontinuity in the process of using or evaluating the 
product [36]. Donald Norman proposed three models of CF [37], namely the design model, user model, and system representation. He also believed that CF would be derived from these three models and the differences between them. Among them, the design model mainly expresses the designer's design concept and represents the designer's cognitive space. The user model is the concept that the product should exist in the user's psychology, including the user's experience and expectations of the product itself, and represents the user's cognitive space. The system representation is the intuitive perception that the product brings to the user and represents the product system itself.

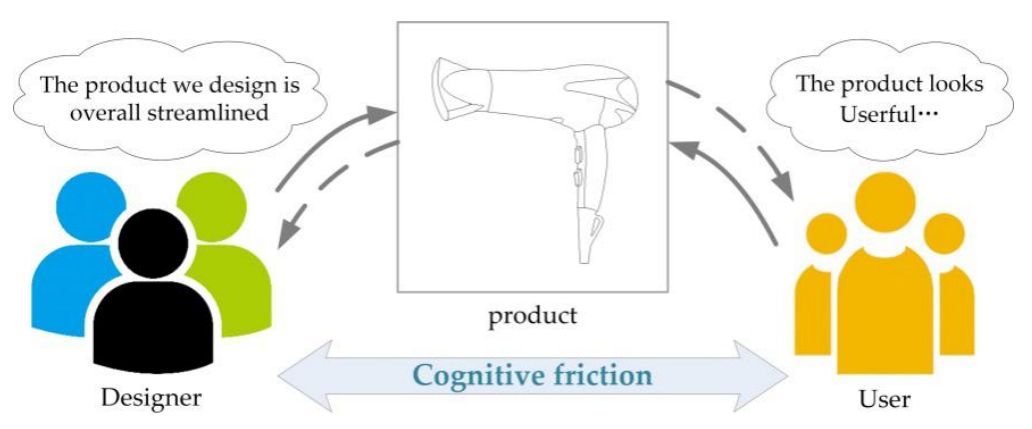

Figure 2. Schematic diagram of cognitive friction $(\mathrm{CF})$ generation.

The design and use of the product are the processes of encoding and decoding. Only by understanding the user's psychological needs can the encoding process be more in line with the user's decoding habits [38]. By making the cognition symmetry, the user's cognitive resistance during the use of the product is reduced to design products that exceed user expectations. Therefore, the effective evaluation and balance of $\mathrm{CF}$ is a key step in improving product design. This paper establishes the $\mathrm{CF}$ evaluation model and balance model between the user and designer. The CF size can be intuitively reflected through the evaluation of the morphological image of the research case and amended through the CF balance model, to filter out the product form that meets the cognition of users and designers. In this way, the cognitive difference between the designer and user can be reduced, and the designer's design efficiency, while meeting the user's psychological needs, can be improved.

\subsection{Game Theory}

Game theory, a method derived from modern mathematics, is used to study decision-making when the behavior of the decision-making subject directly interacts, and the equilibrium problem of such decision-making [39], which is an important method of multi-attribute decision-making. The decision-making subject will consider the other party's decision in his/her own decision-making, choose the strategy that is most beneficial to him/her, and maximize his/her own profits or ultimately win; this strategy is widely used in various fields of life [40]. For example, in product form design, determining the evaluation index weights among cognitive subjects (users, designers, engineers, etc.) is also a key issue in multi-attribute decision-making. Accurate index weights are the basis for obtaining reliability evaluation results. Index weighting methods mainly include three types: the subjective weighting method, objective weighting method, and combined weighting method. The subjective weighting method relies on the experience or knowledge of the cognitive subject and is a subjectively meaningful decision, such as the analytic hierarchy process (AHP) [41]. The objective weighting method relies on the information itself to obtain weight data through calculation, such as the entropy weight method [42-44]. The combined weighting method combines subjective and objective information to determine the weight. In the study of evaluation problems, only a single subjective or objective weighting method cannot accurately express the relationship between the evaluation subjects and the true situation of the evaluated information, which is likely to lead to a lack of information and affect the evaluation results [40]. Based on game theory, the problem of information loss caused by a single weighting can be reduced to a large extent, and accurate evaluation results can be obtained through the combined weighting of the evaluation process of cognitive subjects [29]. 
The process of product design is a process of cognitive information games. As shown in Figure 3, we call it the "cognitive game". The product is the game object, and designers, users, engineers, etc. are the main game subjects. Only two types of cognitive subjects, users and designers, are considered in this paper. Based on users, they hope that the products can fully meet their expectations or emotional needs on the basis of satisfying the functions of the products, and designers believe that the products not only need to meet the needs of users, but should also highlight the design concept and be able to provide users with more than the expected experience effects. However, in the actual design process, due to the ambiguity of the user's perceived information, it will rely more on the designer's subjective image. In the process of product form evaluation, the strongest image of the same product is different between the user and designer, resulting in a gap in image perception between them, so the product designed by the designer cannot be fully accepted by the user, which leads to CF between users and designers. However, users and designers hope that they are the winners of the product image perception evaluation, thus forming a cognitive game between cognitive subjects. Only by balancing CF can the purpose of balancing cognitive games be achieved, and finally the new product's design and development will be more successful. This paper builds a balance model of CF based on game theory and obtains more objective and accurate assessment information to complete the evaluation of product image form and provide designers with a cognitive basis for further product design.

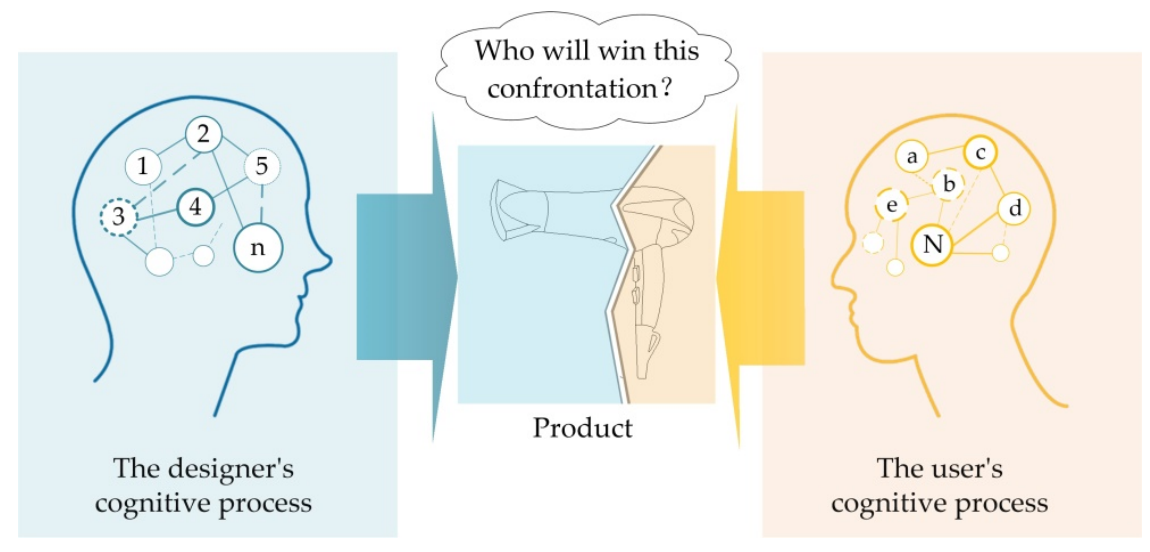

Figure 3. Schematic diagram of the cognitive game process.

\section{Method}

By combining qualitative and quantitative research methods, we establish the flow of the entire study, as shown in Figure 4, including the product form image evaluation, the establishment and application of $\mathrm{CF}$ evaluation model and balance model, and the model verification. First, the collection of picture samples was carried out in various ways and combined with morphological similarity evaluation, to obtain the research sample set. Second, the image vocabulary corresponding to this product was collected on the Internet, and the target image vocabulary was obtained through the SD and image entropy method. Next, based on the target image, fuzzy Theil entropy was used to calculate the CF between users and designers, and the samples were sorted and analyzed based on the size of the index. Then, the CF balance model was established based on the game theory equilibrium thought, to obtain the comprehensive evaluation value of the product form under the target image. Finally, the eye-tracking experiment was used to verify the feasibility of the model. 


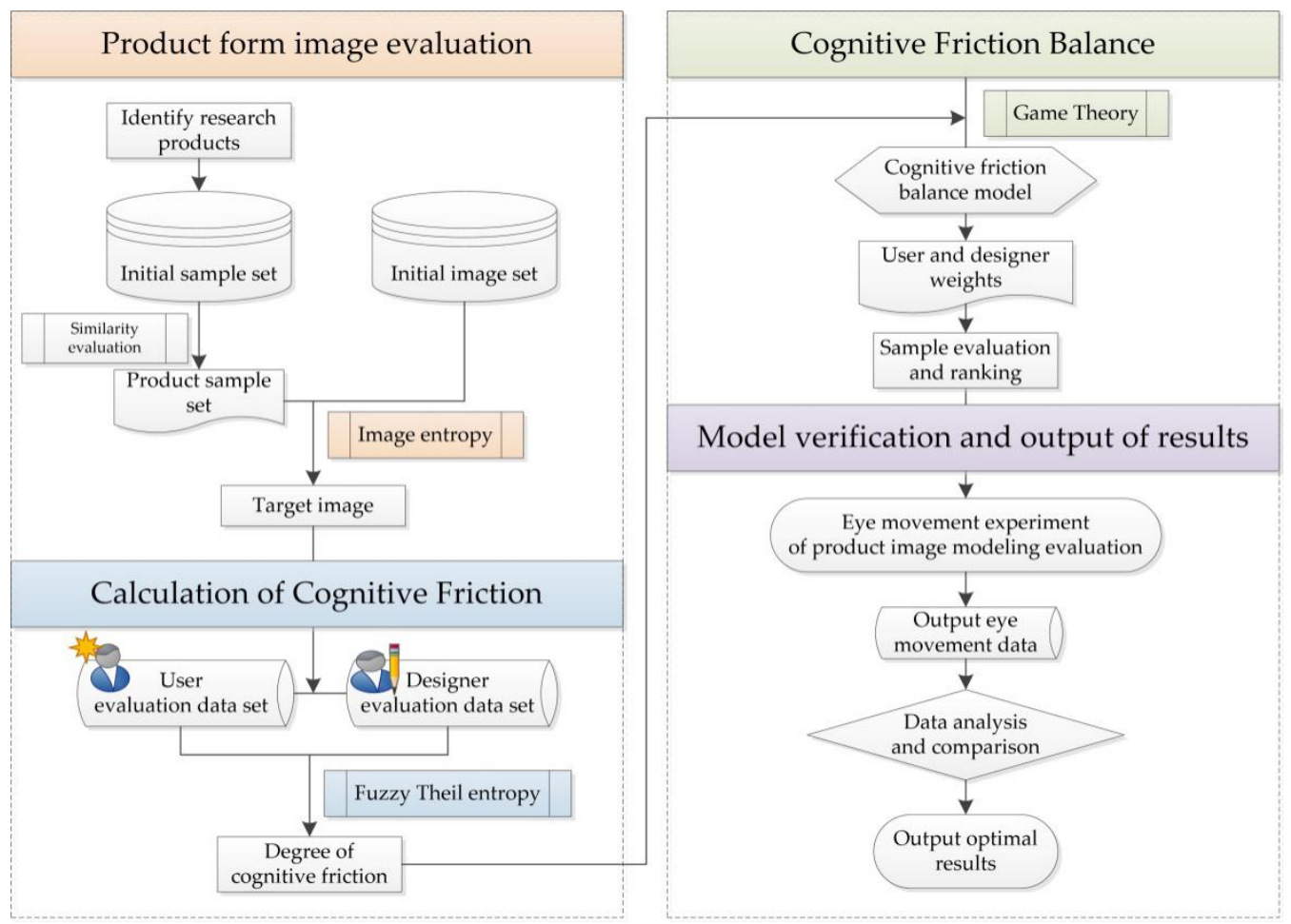

Figure 4. Research framework.

\subsection{Evaluation of Product form Image}

The image is the main form of thinking activity, and it is the conscious activity of the object within the cognitive subject. The image of product form is the language used by the cognitive subject to communicate with the product on the product form, color structure, etc., and is the driving force and direction of the optimal design of the product form. The accuracy of image extraction is related to whether designers and enterprises can effectively design and develop products that meet the user's emotional and functional requirements [45]; in short, its accuracy is directly related to the success or failure of product development. However, due to differences in knowledge background, cognitive thinking, etc., designers and users will have cognitive differences at the cognitive level of the same product [46], thereby leading to CF in the human-machine environment. The target image represents the main evaluation of the product form by the cognitive subject. In an ideal design activity, only when the designer fully understands the user's target image can he/she formulate the corresponding design strategy to match his/her own cognition and the user's cognition and form a state of cognitive equilibrium. At present, researchers usually use the oral analysis method, image scale method, physiological experiment method, etc., to mine the target image of the cognitive subject to the product.

Entropy, as an important indicator in measuring the stability of the system, refers to the degree of system chaos, that is, a measure of the probability of the system when it is in a certain state. The greater the system entropy value is, the greater the probability of being in this state. Information entropy theory was first introduced by Shannon, in the field of thermodynamics [42], as a measure of the negative entropy of the amount of information, indicating the degree of order of the system and reflecting the degree of diversity of the dataset. The greater the degree of diversity is, the greater the weight value of the standard, and conversely, the smaller the weight value. In this paper, based on the principle of information entropy, the evaluation data of users and designers are calculated to obtain the image entropy value of the sample being evaluated, thereby obtaining the weight of each image in 
the image set. The image with the largest weight value is selected as the target image in this paper. The product target image value represented by the entropy value is as follows:

$$
\chi_{j}=-\sigma \sum_{i=1}^{m}\left(P_{i j} \ln P_{i j}\right)
$$

where $\chi_{j}$ represents the image entropy value; $i$ represents the research sample set, $i=1,2,3, \ldots, \mathrm{m}$; $j$ represents the initial target image set, $j=1,2,3, \ldots, \mathrm{n} ; P_{i j}$ represents the probability of the $j$-th image of the $i$-th product sample, $0 \leq P_{i j} \leq 1 ; \sigma$ is a constant; and $\sigma=1 / \ln m$.

The SD method is widely used to quantify the perception of cognitive subjects and is generally divided into five and seven-level evaluations. The five-level evaluation process is shown in Figure 5.

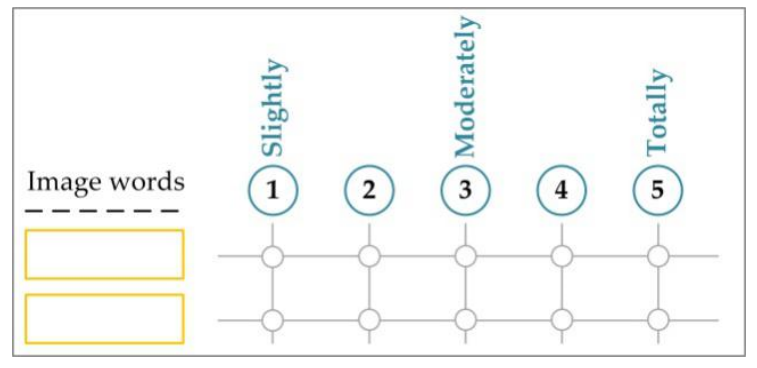

Figure 5. Five-level SD evaluation process.

The five-level SD method is used to evaluate user and designer product image forms in this paper, and an evaluation matrix is established as follows:

$$
X^{\Theta}=\left[\begin{array}{cccc}
X_{11}^{\Theta} & X_{12}^{\Theta} & \ldots & X_{1 n}^{\Theta} \\
X_{21}^{\Theta} & X_{22}^{\Theta} & \ldots & X_{2 n}^{\Theta} \\
\vdots & \vdots & X_{i j}^{\Theta} & \vdots \\
X_{m 1}^{\Theta} & X_{m 2}^{\Theta} & \ldots & X_{m n}^{\Theta}
\end{array}\right]
$$

where $\Theta$ represents the cognitive subject; $\Theta=1,2$ represents the user and designer, respectively; and $X_{i j}^{\Theta}$ represents the evaluation value of the $j$-th image of the $i$-th sample by the $\Theta$-type cognitive subject.

To reduce the error of the cognitive subject in the evaluation process, the evaluation matrix, $X^{\Theta}$, is normalized to obtain the image decision matrix, $\stackrel{\Theta}{\Theta}^{\Theta}$, and then the probability $P_{i j}$ of the image is obtained as follows:

$$
P_{i j}=y_{i j} / \sum_{j=1}^{n}\left(1-\chi_{j}\right)
$$

where $y_{i j}$ is the normalized data of the $j$-th image of the $i$-th sample.

Using Formula (1) to calculate the probability $P_{i j}$ of each image to obtain the entropy value of the $j$-th image, we see the weight $W_{j}$ of the image in the entire evaluation process is as follows:

$$
W_{j}=\left(1-\chi_{j}\right) / \sum_{j=1}^{n}\left(1-\chi_{j}\right)
$$

According to the weight value of each image, the largest image is selected as the target image of this study. 


\subsection{Evaluation of $C F$}

Due to differences in knowledge, experience, environment, etc., for the same product, the perception model generated by the user is different from that of the designer. Though users focus on the function, appearance, manner of use, etc., the designer is concerned with the imagery feeling, such as inspiration, beauty, and experience, which is the designer's invisible knowledge. This causes $\mathrm{CF}$ between them. In the actual design process, only when the designer conducts in-depth research on the user's perception and accurately grasps the user's perceptual knowledge can the design scheme be successful, thereby improving design efficiency. Therefore, the first step of design is to evaluate the CF between the user and designer so that the designer can grasp the difference and size of his/her cognitive difference with the user. It is convenient for designers to adjust the design ideas in time, to achieve cognitive symmetry with users.

Theil entropy, also known as the Theil index, is a statistic used by the Dutch economist Theil in 1967 to measure economic inequality [47] and is also commonly used in econometrics as a measure of relative difference. It is commonly used as an assessment of regional development differences, also known as inequality. The larger the value is, the greater the difference in development. This indicator usually represents the inequality between the subgroups of a group in the form of a weighted sum. According to the demand, it can also be decomposed to obtain the measurement of the contribution of intragroup and intergroup differences to system differences and to reveal the impact of intragroup and intergroup differences on the entire system.

According to the needs of this research, the fuzzy Theil entropy value is used to characterize the CF of the two groups of users and designers on the same product; that is, fuzzy Theil entropy is used to represent CF. For sample $i$, the expression of the Theil entropy index is as follows:

$$
T^{i}=\left(X_{i}^{1} / X_{i}^{1}+X_{i}^{2}\right) \ln \frac{\left(X_{i}^{1} / \alpha\right)(\alpha+\beta)}{\left(X_{i}^{1}+X_{i}^{2}\right)}+\left(X_{i}^{2} / X_{i}^{1}+X_{i}^{2}\right) \ln \frac{\left(X_{i}^{2} / \beta\right)(\alpha+\beta)}{\left(X_{i}^{1}+X_{i}^{2}\right)}
$$

where $X_{i}^{1}$ and $X_{i}^{2}$ represent the sum of the evaluation values of all users and designers on sample $i$, respectively; and $\alpha$ and $\beta$ represent the number of users and designers, respectively.

For sample $i$, the CF $F_{r}^{i}$ between users and designers is as follows:

$$
F_{r}^{i}=T^{i} / \sum_{i=1}^{m} T^{i}
$$

\subsection{Construction of the CF Balance Model}

In Section 3.2, we evaluated the value of CF. To achieve cognitive balance in the evaluation process of sample modelling images, we establish a CF balance model. In the above sections, we introduced game theory in detail. Because of its obvious advantages in balancing decision-making, this paper builds a CF balance model based on game theory. The cognitive weights of users and designers are participants, and the final comprehensive weight vector is a balanced decision. Then, we proceed as follows:

Step 1: According to the evaluation value of the target image of the sample product by the user and designer, cognitively weight the user and designer to obtain the basic weight vector set $\lambda=\left\{\lambda_{1}, \lambda_{1}, \ldots, \lambda_{k}\right\}(k=1,2, \ldots, m)$.

$$
\lambda_{i}=\left(\frac{X_{i}^{1}}{X_{i}^{1}+X_{i}^{2}}, \frac{X_{i}^{2}}{X_{i}^{1}+X_{i}^{2}}\right)
$$


Mark any linear combination of $m$ different vectors, as follows:

$$
\lambda=\sum_{k=1}^{m} \omega_{k} \lambda_{k}^{T}
$$

where $\omega_{k}>0, \sum_{k=1}^{m} \lambda_{k}=1, \lambda$ is any possible weight vector in the weight set, and $\omega_{k}$ is the linear combination coefficient.

Step 2: Optimize $m$ linear combination coefficients $\omega_{k}$ by applying game theory to minimize the deviation between $\lambda$ and each $\lambda_{k}$, as follows:

$$
\min \left\|\sum_{k=1}^{m} \omega_{k} \lambda_{k}^{T}-\lambda_{\eta}\right\|_{2}(\eta=1,2, \ldots, m)
$$

According to the differential properties of the matrix, Equation (10) can be used to express the optimal first derivative condition in Equation (9):

$$
\sum_{k=1}^{m} \omega_{k} \lambda_{\eta} \lambda_{k}^{T}=\lambda_{\eta} \lambda_{\eta}^{T}(\eta=1,2, \ldots, m)
$$

Converting it to a linear formula, Formula (11) is as follows:

$$
\left[\begin{array}{cccc}
\lambda_{1} \lambda_{1}^{T} & \lambda_{1} \lambda_{2}^{T} & \ldots & \lambda_{1} \lambda_{m}^{T} \\
\lambda_{2} \lambda_{1}^{T} & \lambda_{2} \lambda_{2}^{T} & \ldots & \lambda_{2} \lambda_{m}^{T} \\
\vdots & \vdots & \ddots & \vdots \\
\lambda_{m} \lambda_{1}^{T} & \lambda_{m} \lambda_{2}^{T} & \ldots & \lambda_{m} \lambda_{m}^{T}
\end{array}\right]\left[\begin{array}{c}
\omega_{1} \\
\omega_{2} \\
\vdots \\
\omega_{m}
\end{array}\right]=\left[\begin{array}{c}
\lambda_{1} \lambda_{1}^{T} \\
\lambda_{2} \lambda_{2}^{T} \\
\vdots \\
\lambda_{m} \lambda_{m}^{T}
\end{array}\right]
$$

Step 3: Calculate $\left(\omega_{1}, \omega_{2}, \ldots, \omega_{m}\right)$ through Formula (11), and normalize it to obtain the following:

$$
\omega_{k}^{*}=\left|\omega_{k}\right| / \sum_{k=1}^{m}\left|\omega_{k}\right|
$$

Therefore, the most satisfying user and designer cognitive weight vectors are as follows:

$$
\omega^{*}=\sum_{k=1}^{m} \omega_{k}^{*} \omega_{k}^{T}
$$

According to $\omega^{*}$, the evaluation value of each sample image form based on CF balance can be calculated as follows:

$$
X_{i}=\sum_{\Theta=1}^{2} \omega_{\Theta}^{*} X_{i}^{\Theta}
$$

Therefore, according to the size of $X_{i}$, the sample image form after the CF balance can be sorted.

\subsection{Model Verification}

To verify the reliability of the CF balance model, an eye-tracking experiment is used to evaluate the results. The entire verification process is completed based on the stages, like experimental design, eye-tracking-equipment calibration, and data output and analysis. Finally, there comes an optimal evaluation result through comparison. 


\section{Case Study}

According to market research, this paper verified the feasibility of the CF evaluation method and balance model through the image form evaluation of household hair dryers. The model method is also applicable to other products.

\subsection{Determination of the Sample and Its Target Image}

Combined with the hair dryer, a total of 128 sample pictures were collected from product sales websites, periodicals, etc. The authoritative designer conducted a preliminary screening from the form, brand, and other aspects, and obtained a total of 36 initial sample sets. To avoid the influence of external factors such as color and brand, line manuscript processing and numbering were used. Then, the SD method was used to create a product form similarity evaluation questionnaire. Twenty-eight students majoring in design conducted form similarity evaluation, and the K-means clustering method was used to cluster the evaluation results. Thirty-six sample images were clustered into 12 categories, and the clustering results are shown in Table 1. The sample closest to the clustering center of each cluster from each category was selected as a representative to form a research sample set, as shown in Figure 6.

Table 1. Initial sample clustering results.

\begin{tabular}{|c|c|c|c|c|c|}
\hline Category & Sample & Category & Sample & Category & Sample \\
\hline 1 & $12,13^{*}, 14$ & 5 & $33^{*}$ & 9 & $30^{*}$ \\
\hline 2 & $\begin{array}{r}2,18,19,20 \\
21^{*}, 22,23,34\end{array}$ & 6 & $6^{*}$ & 10 & $10,29^{*}$ \\
\hline 3 & $3^{*}, 7,25,26$ & 7 & $24,28^{*}, 35,36$ & 11 & $8,9,16,17^{*}, 31$ \\
\hline 4 & $4^{*}$ & 8 & $32^{*}$ & 12 & $1^{*}, 5,11,15,27$ \\
\hline \multicolumn{6}{|c|}{ Selected samples are marked with “*”. } \\
\hline & & & & & \\
\hline $\mathrm{S}_{1}$ & $\mathrm{~S}_{2}$ & $\mathrm{~S}_{3}$ & $\mathrm{~S}_{4}$ & S5 & $\mathrm{S}_{6}$ \\
\hline & & & & & \\
\hline $\mathrm{S}_{7}$ & S8 & S9 & $\mathrm{S}_{10}$ & $\mathrm{~S}_{11}$ & $\mathrm{~S}_{12}$ \\
\hline
\end{tabular}

Figure 6. Study sample set.

According to the evaluation of users on the hair-dryer sales website, the initial target image vocabulary of this study is extracted as follows: "Simplicity", "Streamlined", "Individuality", "Holistic", "Advanced", and "Useful". To ensure the fairness and rationality of designers and users in the evaluation process, eight designers, each with experience in hair-dryer-form design, and users, each with experience in the frequent use of hair dryers, were selected to form two types of cognitive subjects. A five-level SD questionnaire was used to construct the evaluation process of cognitive subjects. Before the evaluation began, the purpose of the study and the evaluation process were fully explained to the participants, and the evaluation experiment was started after obtaining their consent or confirmation. To ensure that the evaluation results of the participants were not affected by the order of the samples, in the design of the SD questionnaire, the order in which the samples appeared was set to be random, thus ensuring the maximum scientific accuracy of the evaluation results. The evaluation results are shown in Table 2. 
Table 2. Evaluation values of the initial target image of the product samples.

\begin{tabular}{ccccccc}
\hline & Simplicity & Streamlined & Individuality & Holistic & Advanced & Useful \\
\hline $\mathrm{S}_{1}$ & 2.50 & 4.00 & 2.88 & 1.81 & 3.06 & 2.75 \\
$\mathrm{~S}_{2}$ & 3.38 & 3.13 & 3.56 & 2.69 & 2.50 & 2.69 \\
$\mathrm{~S}_{3}$ & 3.25 & 2.69 & 2.63 & 2.06 & 2.63 & 3.06 \\
$\mathrm{~S}_{4}$ & 4.13 & 1.50 & 3.13 & 3.13 & 2.13 & 3.19 \\
$\mathrm{~S}_{5}$ & 4.19 & 2.38 & 2.00 & 3.69 & 2.31 & 3.81 \\
$\mathrm{~S}_{6}$ & 3.44 & 1.88 & 2.63 & 3.13 & 2.44 & 3.50 \\
$\mathrm{~S}_{7}$ & 3.56 & 3.56 & 2.38 & 3.19 & 3.00 & 3.69 \\
$\mathrm{~S}_{8}$ & 2.19 & 3.75 & 3.81 & 1.63 & 2.63 & 3.00 \\
$\mathrm{~S}_{9}$ & 2.19 & 3.75 & 3.69 & 1.63 & 2.25 & 2.44 \\
$\mathrm{~S}_{10}$ & 2.69 & 1.94 & 3.06 & 3.38 & 2.75 & 2.31 \\
$\mathrm{~S}_{11}$ & 3.69 & 1.81 & 2.38 & 4.19 & 2.94 & 2.94 \\
$\mathrm{~S}_{12}$ & 4.50 & 1.38 & 3.56 & 4.06 & 3.94 & 4.06 \\
\hline
\end{tabular}

From Table 2, the weight value of each image vocabulary was obtained by using Formulas (3) and (4), as shown in Figure 7. It can be seen from the results that the "Holistic" image weight is higher, while the "Individuality" image weight is lower. Therefore, "Holistic" is selected as the target image of this paper.

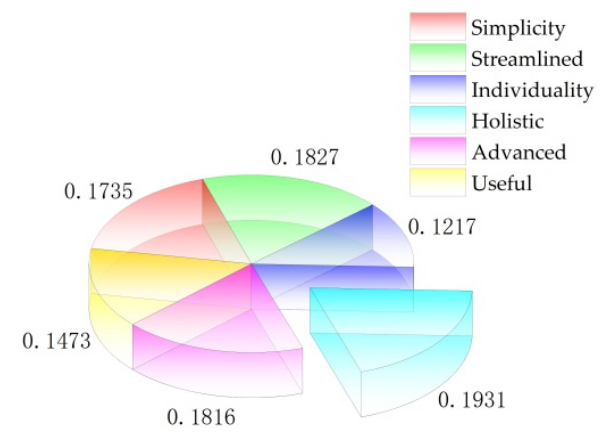

Figure 7. Weighted values of each image vocabulary.

\subsection{Research on CF Evaluation Based on Target Image}

Eight experienced designers and eight typical users were selected as the expert group to evaluate the target image of the research samples, and the evaluation results are shown in Table 3. According to Formulas (5) and (6), the degree of CF between two cognitive subjects can be seen in Figure 8.

Table 3. Evaluation results of users and designers.

\begin{tabular}{ccccccccccccc}
\hline Sample & $\mathbf{S}_{\mathbf{1}}$ & $\mathbf{S}_{\mathbf{2}}$ & $\mathbf{S}_{\mathbf{3}}$ & $\mathbf{S}_{\mathbf{4}}$ & $\mathbf{S}_{\mathbf{5}}$ & $\mathbf{S}_{\mathbf{6}}$ & $\mathbf{S}_{\mathbf{7}}$ & $\mathbf{S}_{\mathbf{8}}$ & $\mathbf{S}_{\mathbf{9}}$ & $\mathbf{S}_{\mathbf{1 0}}$ & $\mathbf{S}_{\mathbf{1 1}}$ & $\mathbf{S}_{\mathbf{1 2}}$ \\
\hline $\mathrm{Au}$ & 2.13 & 2.63 & 2.13 & 3.00 & 3.88 & 3.38 & 3.00 & 2.13 & 1.88 & 3.88 & 4.63 & 4.00 \\
$\mathrm{Su}$ & 17 & 21 & 17 & 24 & 31 & 27 & 24 & 17 & 15 & 31 & 37 & 32 \\
$\mathrm{Ad}$ & 1.50 & 2.75 & 2.00 & 3.25 & 3.50 & 2.88 & 3.38 & 1.13 & 1.38 & 2.88 & 3.75 & 4.13 \\
$\mathrm{Sd}$ & 12 & 22 & 16 & 26 & 28 & 23 & 27 & 9 & 11 & 23 & 30 & 33 \\
\hline
\end{tabular}

Au represents the average of user evaluation values; Su represents the sum of user evaluation values; Ad represents the average of designer evaluation values; Sd represents the sum of designer evaluation values. 


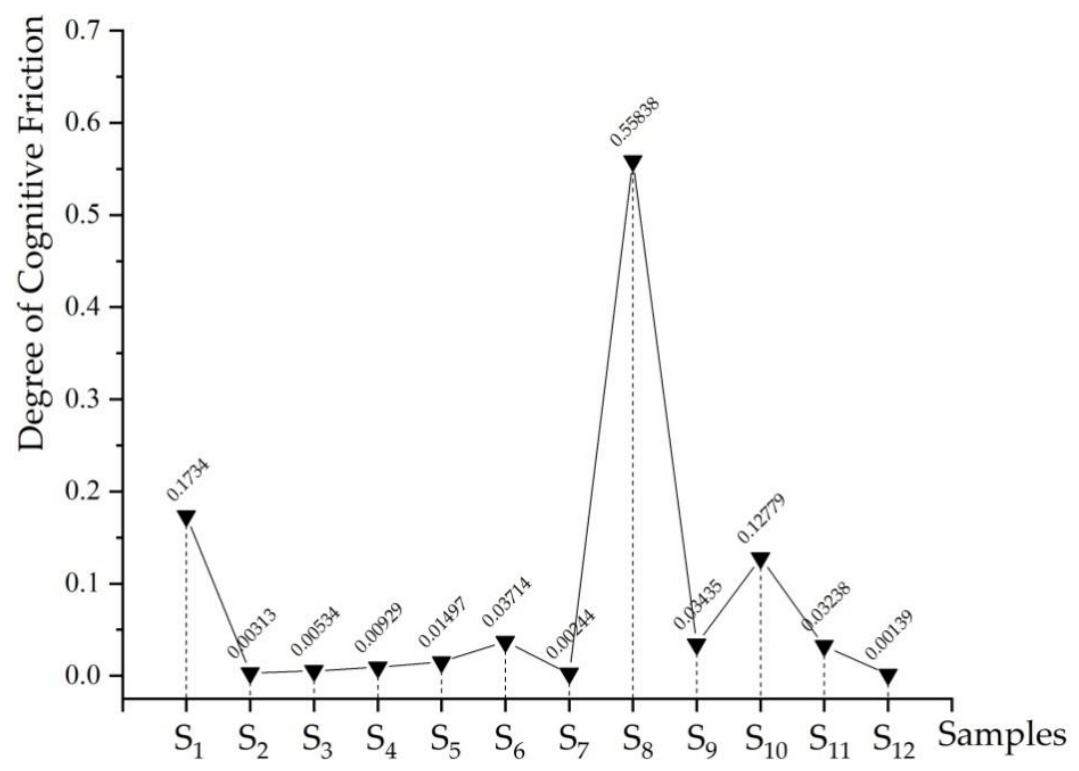

Figure 8. Degree of CF between cognitive subjects, based on target image.

According to Figure 8, the smallest CF value of 0.00139 is obtained for sample $S_{12}$, while the largest is obtained for sample $S_{8}$. The degree of $C F$ is ranked as follows: $S_{8}>S_{1}>S_{10}>S_{6}>S_{9}>S_{11}>$ $\mathrm{S}_{5}>\mathrm{S}_{4}>\mathrm{S}_{3}>\mathrm{S}_{2}>\mathrm{S}_{7}>\mathrm{S}_{12}$.

\subsection{Research on CF Balance}

According to the CF balance model constructed in Section 3.3, by using Formula (7), the calculated $\lambda$ results based on the evaluation data of users and designers are shown in Table 4 . Then, the cognitive weight vector of users and designers is obtained as 0.56 and 0.44 , respectively, by using Formulas (8)-(13). The comprehensive evaluation value of each sample based on the target image was calculated by Formula (14), which is shown in Table 5.

Table 4. $\lambda$ value.

\begin{tabular}{cccccc}
\hline$\lambda_{1}$ & $\lambda_{\mathbf{2}}$ & $\lambda_{\mathbf{3}}$ & $\lambda_{\mathbf{4}}$ & $\lambda_{\mathbf{5}}$ & $\lambda_{\mathbf{6}}$ \\
\hline$(0.59,0.41)$ & $(0.49,0.51)$ & $(0.52,0.48)$ & $(0.48,0.52)$ & $(0.53,0.47)$ & $(0.54,0.46)$ \\
\hline$\lambda_{\mathbf{7}}$ & $\lambda_{\mathbf{8}}$ & $\lambda_{\mathbf{9}}$ & $\lambda_{\mathbf{1 0}}$ & $\lambda_{\mathbf{1 1}}$ & $\lambda_{\mathbf{1 2}}$ \\
\hline$(0.47,0.53)$ & $(0.65,0.35)$ & $(0.58,0.42)$ & $(0.57,0.43)$ & $(0.55,0.45)$ & $(0.51,0.49)$ \\
\hline
\end{tabular}

Table 5. Comprehensive evaluation values of samples.

\begin{tabular}{cccccccccccc}
\hline $\mathrm{S}_{\mathbf{1}}$ & $\mathrm{S}_{\mathbf{2}}$ & $\mathrm{S}_{\mathbf{3}}$ & $\mathrm{S}_{\mathbf{4}}$ & $\mathrm{S}_{\mathbf{5}}$ & $\mathrm{S}_{\mathbf{6}}$ & $\mathrm{S}_{\mathbf{7}}$ & $\mathrm{S}_{\mathbf{8}}$ & $\mathrm{S}_{\mathbf{9}}$ & $\mathrm{S}_{\mathbf{1 0}}$ & $\mathrm{S}_{\mathbf{1 1}}$ & $\mathrm{S}_{\mathbf{1 2}}$ \\
\hline 1.85 & 2.68 & 2.07 & 3.11 & 3.71 & 3.16 & 3.17 & 1.69 & 1.66 & 3.44 & 4.24 & 4.06 \\
\hline
\end{tabular}

Combined with the original evaluation data of users and designers, the sample order after CF balance is shown in Figure 9. It can be seen from the figure that the original evaluation value contains two cognitive subjects of the user and the designer, and there is a large gap of the evaluation value among some samples, such as $\mathrm{S}_{1}, \mathrm{~S}_{8}, \mathrm{~S}_{10}$, and $\mathrm{S}_{11}$. This leads to the asymmetry of cognitive information in the evaluation process of product samples and makes decision makers unable to obtain effective evaluation information accurately. After the evaluation of the quantitative CF balance model, the evaluation information of users and designers can be calculated reasonably and comprehensively, and each sample can obtain comprehensive evaluation results, which makes the evaluation information of the sample target image more accurate and reasonable, and improves the efficiency of decision-making. 


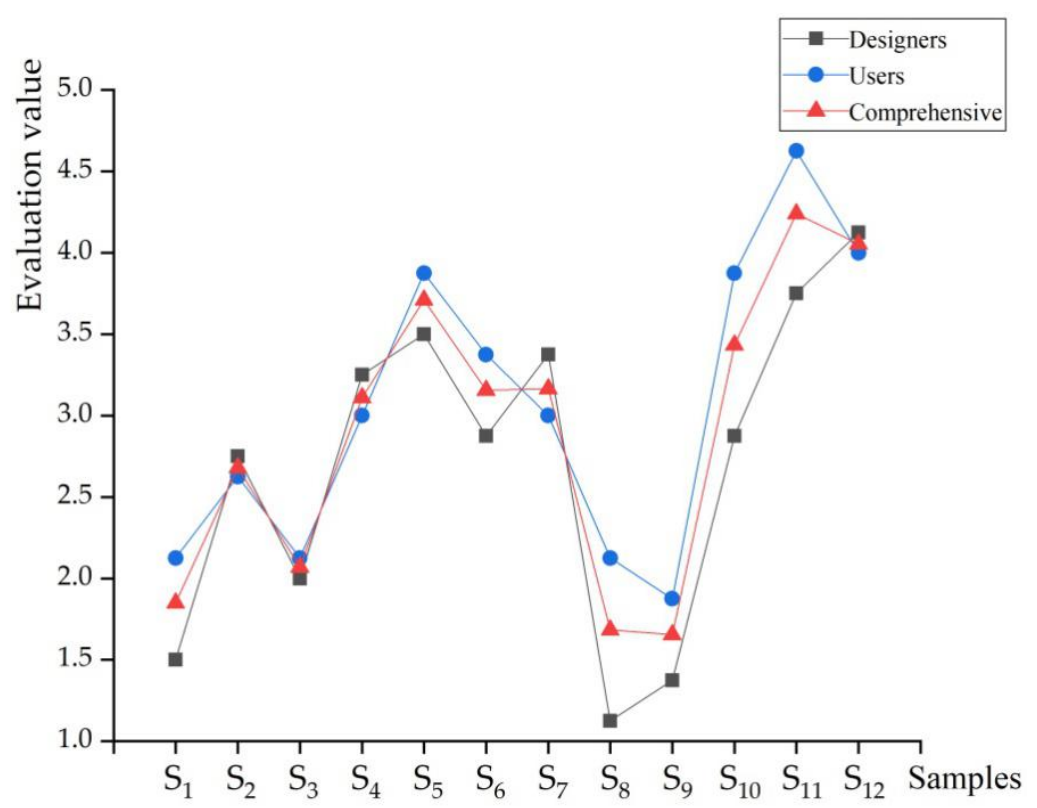

Figure 9. Comparison of the evaluation of sample image form.

For all samples, the comprehensive evaluation value of sample $S_{11}$ is the highest, which is 4.24; $S_{9}$ is the lowest, which is 1.66. The ranking of all comprehensive evaluations is as follows: $S_{11}>S_{12}$ $>S_{5}>S_{10}>S_{7}>S_{6}>S_{4}>S_{2}>S_{3}>S_{1}>S_{8}>S_{9}$. For sample $S_{11}$, its user evaluation value has an absolute advantage in all samples, while the user evaluation value of $S_{9}$ is the lowest, which shows that the user evaluation participation is essential in the early stage of product development.

\subsection{Result Verification}

To increase the credibility of the comprehensive evaluation results, we used the eye movement experiment [48] for verification. The experiment uses a Tobii X2-30 eye tracker with the ErgoLAB software installed on an ASUS 14-inch display for the experimental process and data processing analysis.

During the design of the experiment, samples $S_{1} \sim S_{12}$ were uniformly sized and put into the experimental material with a white background. Each sample was preset as an area of interest (AOI), and then a total of 12 AOIs were formed in the experimental material: AOIS1, AOIS2, AOIS3, AOIS4, AOIS5, AOIS6, AOIS7, AOIS8, AOIS9, AOIS10, AOIS11, and AOIS12, as shown in Figure 10. Five graduate students (with both design-thinking and product-use experience) were randomly selected from the design profession as participants to participate in the experiment, including 3 males and 2 females, all without colour blindness and colour weakness and with corrected vision of 1.0 and above. To ensure the reliability of the experimental results, before the start of the experiment, only the experimental operation process was trained, and the participant of the experiment was not informed. The experiment guideline was set as follows: "please select the sample you think is the most "Holistic" and tap "space" to go to the next page". The experimental process is shown in Figure 11.
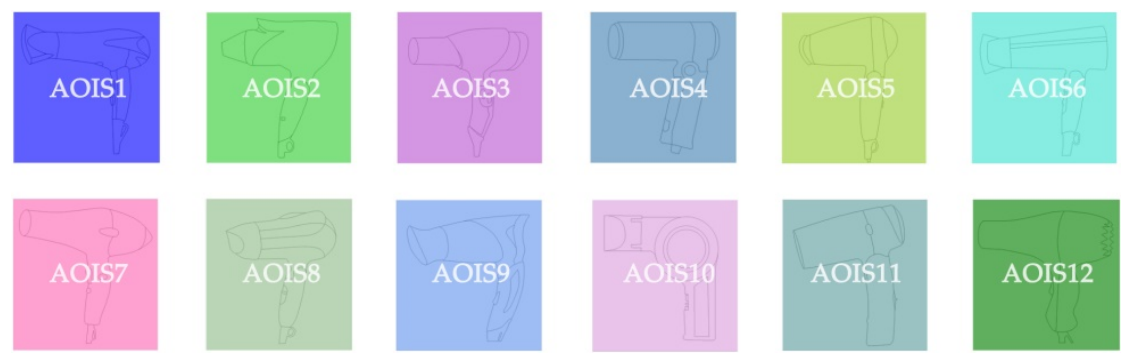

Figure 10. Areas of interest (AOIs) of the sample. 


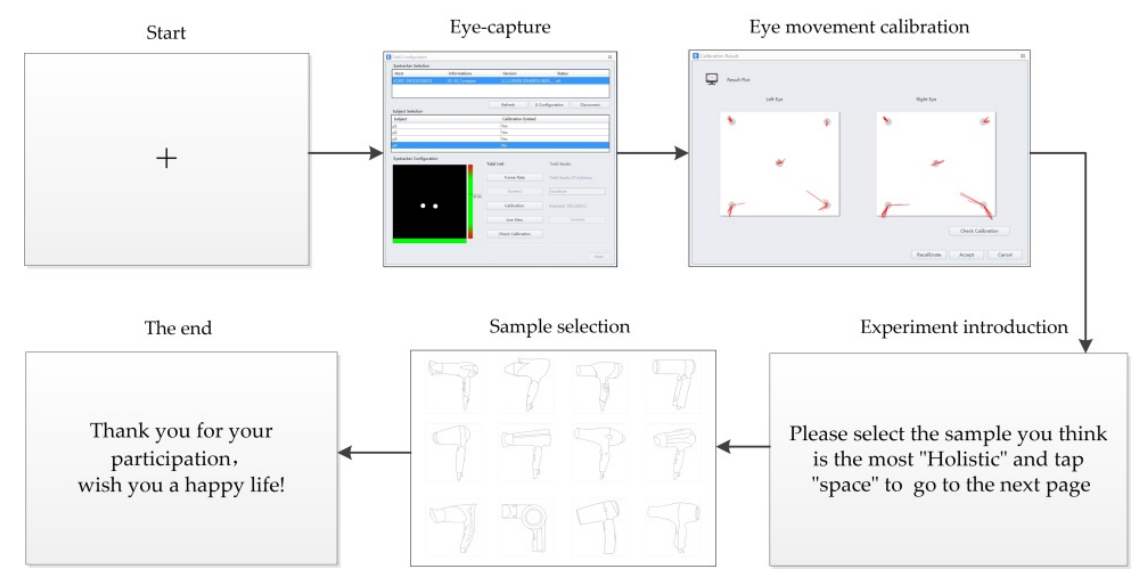

Figure 11. Flow of eye movement experiment (during the actual experiment, the introduction and end are expressed in Chinese).

Five participants completed the experiment in turn and received a small gift as a reward. The "Time to First Fixation", "Fixation Duration", and "Fixation Count" were taken in AOI as statistical objects. According to the recorded data of ErgoLAB, for all AOIs, the final statistical results are shown in Figure 12. It can be seen from the comprehensive data in the figure that, for the "Time to First Fixation" of AOI, sample $\mathrm{S}_{12}$ is the highest. However, comparing the "Fixation Duration" and "Fixation Count" of each participant and the total, we see sample $S_{11}$ is much more concerning than sample $S_{12}$. This shows that, when looking at the sample for the first time, sample $S_{12}$ will be attractive, but after repeated comparisons, most of the participants will finally choose sample $S_{11}$ as the sample that is most "Holistic". This conclusion can also be drawn from the eye movement trajectory of Figure 13 and the heat map of Figure 14, which is consistent with the comprehensive evaluation results in Section 4.3. Therefore, the balance model of $\mathrm{CF}$ is effective and feasible in the actual evaluation process. In the subsequent design of the form of the hair dryer, sample $\mathrm{S}_{11}$ can be used as a design reference for the "Holistic" target image.

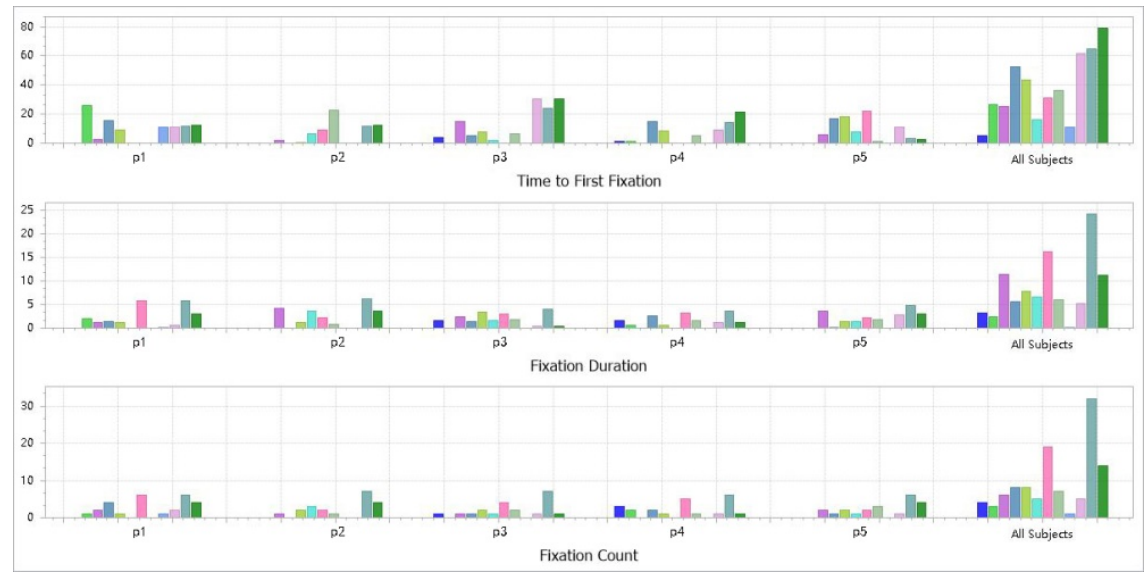

Figure 12. Eye movement data statistics. 


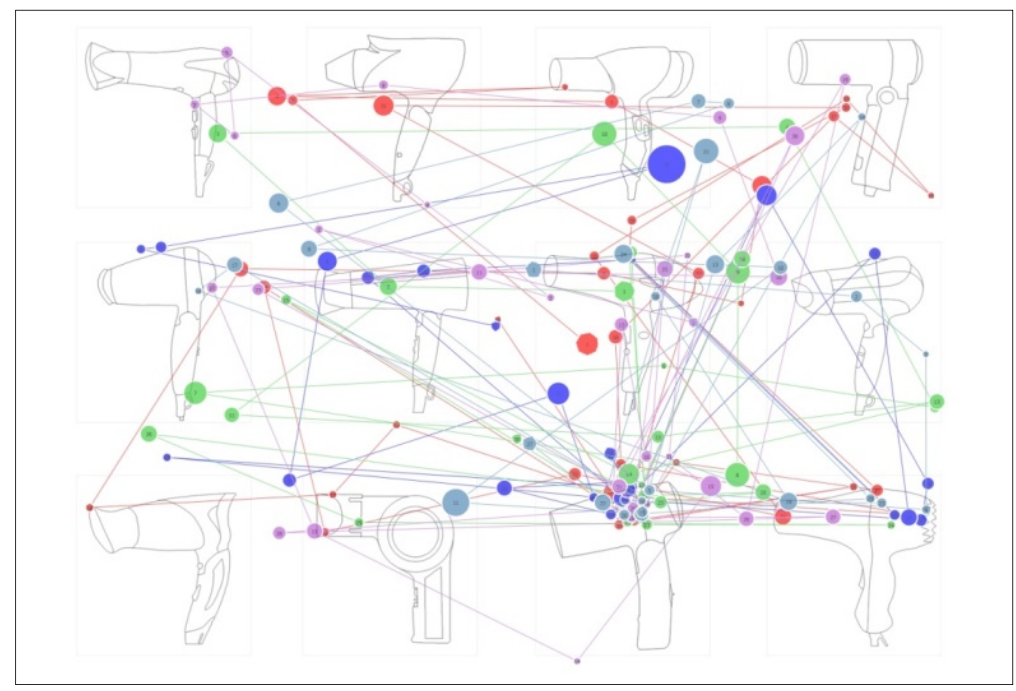

Figure 13. Eye movement trajectories.

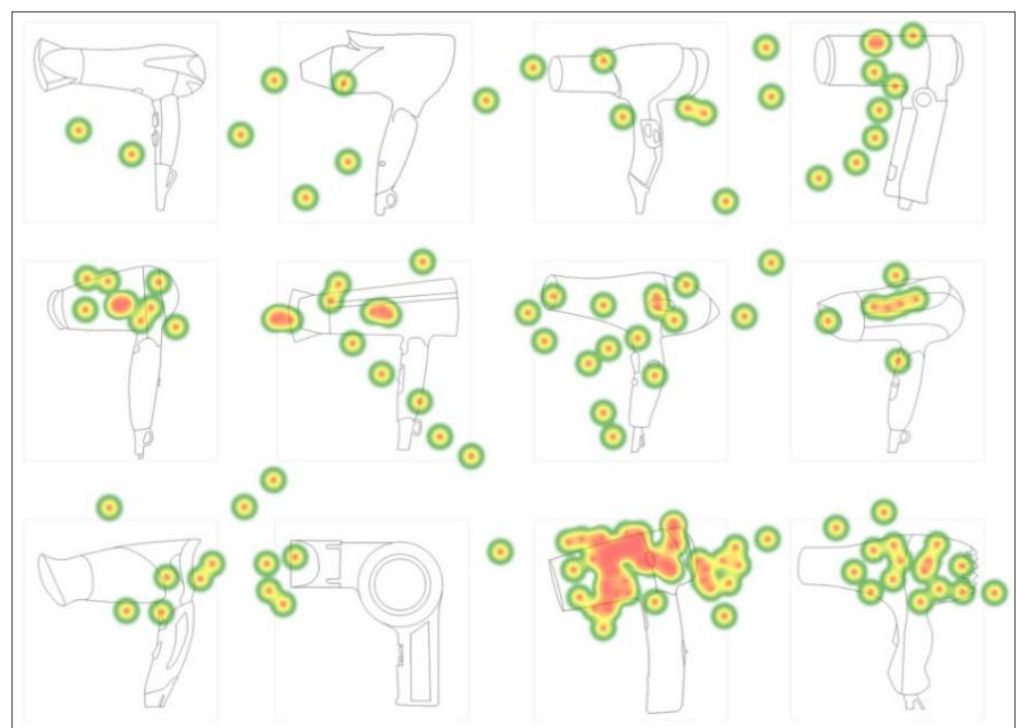

Figure 14. Eye movement heat map.

\section{Discussion}

\subsection{Evaluation of the Paper Results}

It can be seen from the results that the best reference of the designer's sample $S_{12}$ has a significant cognitive gap with the user's sample $S_{11}$ as being the most holistic image. Research on the CF balance is a necessary step in the product development process. After comprehensive evaluation, sample $S_{11}$ with the highest value is obtained as the main reference sample for the form design based on the target "Holistic" image. The detailed analysis shows that the designers judge that sample $S_{12}$ has a more holistic nature through the unity of form and the lack of excessive decorative lines on the surface. However, the user thinks that the tail of sample $S_{12}$ is more fragmented, and its functionality is weaker, while the overall appearance of sample $S_{11}$ is clean and tidy, with a more holistic image. Therefore, designers often combine their own experience to pay attention to the overall feeling of the product in the evaluation process, while users pay more attention to details and functions.

From the perspective of $C F$ evaluation, sample $S_{8}$ has the largest $C F$, which is much higher than that of the other samples. However, it can be seen from the final comprehensive evaluation value that the evaluation value of sample $S_{8}$ is not the lowest, and although the CF of sample $S_{12}$ is the smallest 
in the entire evaluation sample set, this is not the case in the final preferred sample. Therefore, it can be considered that it is not that the CF between cognitive subjects is as small as possible in the design process. CF can be used only as a reference in the image evaluation process, and the preferred sample will appear at the minimum value of nearby CF. A question for future research is as follows: What is the specific range of $C F$ that is more in line with the evaluation criteria? Similarly, in the research on CF balance, game theory has played an important role in establishing a balance model, which also illustrates the feasibility and necessity of using game theory in cognitive science research.

\subsection{Evaluation of the $C F$}

Due to the difference in professional background and thinking styles between cognitive subjects, different cognitive subjects have obvious differences in perception and expression of product characteristics when designing products, which leads to the asymmetry of cognitive information. The concept of $\mathrm{CF}$ was presented to intuitively show the differentiation. However, the existing literature $[9,10,49]$ only quotes the concept of $C F$, and the actual research is still on cognitive asymmetry, which is not expressed at a quantitative level, so the assessment of CF remains at a qualitative level. The size of $\mathrm{CF}$ and the mechanism of its generation are still unobservable and predictable. For designers, it is still impossible to accurately grasp the cognitive asymmetry between the product design process and the user. This research is a further study of $\mathrm{CF}$, using fuzzy Theil entropy to quantitatively calculate the size of $\mathrm{CF}$, so the cognitive subject can intuitively feel the asymmetry, and it can provide theoretical guidance for designers in the product design process.

\subsection{Cognitive Symmetry}

In the field of product design, the cognitive balance between cognitive subjects is an essential research step, which is called "cognitive symmetry". Only after the cognition between cognitive subjects reaches symmetry can designers grasp the emotional needs of users or other cognitive subjects more accurately, and thus complete product development more efficiently. The research of user needs is the first step of product development plan, and the designer is both the implementer of research and the undertaker of design work. Therefore, both the user and the designer play an indispensable role in the product design. Comprehensive user's emotional needs and designer's design thinking or experience are necessary to guarantee the success of product development. Though Quan et al. [29] combined Kansei engineering and game theory methods to complete product recommendations to users, they did not take the designer into account, so the cognitive subject was relatively single. Su et al. [42] took the perceptual cognition of users, designers, and engineers into consideration, but they used a more subjective AHP method in the process of cognitive balance. Similarly, Yang et al. [38] used the subjective form of questionnaires and interviews to comprehensively evaluate the cognitive differences between designers and users. This paper comprehensively considers the cognitive differences between users and designers. Based on the advantages of game theory in system evolution and balance, we establish a cognitive balance model between cognitive subjects and complete a quantitative cognitive symmetry study, which makes the evaluation process more reasonable.

\section{Conclusions}

In order to realize the symmetry and balance between cognitive subjects (users and designers) and achieve the purpose of comprehensive evaluation of product image forms among different cognitive subjects, this paper proposes a CF evaluation and balance model combining fuzzy Theil entropy and game theory to obtain the product form under the target image, and the evaluation results are verified by eye movement experiments. First, a CF evaluation system is established based on image entropy and fuzzy Theil entropy, and the CF between users and designers is evaluated for the samples. Then, combined with game theory ideas, a cognitive friction balance model is constructed, comprehensive evaluation weights between cognitive subjects are obtained, and sample forms are comprehensively sorted. This paper takes the form of a household hair dryer as an example to verify 
the effectiveness and feasibility of the entire process. Compared with current researches, this paper adopts a new theoretical method to quantify the $\mathrm{CF}$ at a perceptual level and visually demonstrate it. With the advantages in system evolution and balance, the game theory is applied to the comprehensive evaluation of the weight between cognitive subjects to obtain the target image form more accurately and efficiently. The main conclusions are as follows. (1) Through the calculation of fuzzy Theil entropy, the evaluation of $\mathrm{CF}$ between users and designers is completed. In the design process, designers can grasp the cognitive asymmetry with users quantitatively and improve the design efficiency and product development success rate. (2) Game theory, as the thinking of balancing the pursuit of optimal expectations by both parties of interest, can be effectively used to establish a CF model between balancing cognitive subjects to achieve cognitive symmetry and then achieve the purpose of balancing cognitive differences. This also introduces new thinking and methods for cognitive science research. (3) The research on the evaluation and balance of CF provides a certain research method for grasping and predicting emotional preferences in product intelligent design. The shortcomings and prospects of this research are listed as follows. (1) This paper defines only cognitive subjects as users and designers, but in the actual product life cycle, cognitive subjects also include engineers, decision makers, and product recyclers. The application of the CF evaluation and balance model on multiple cognitive subjects is not verified in this paper. (2) In order to mine the intuitive feelings of users and designers, the evaluation data of this paper were obtained by using the five-level SD method, which is relatively simple to acquire. In the future, we will consider using a combination of physiological measurement and psychological evaluation to obtain relevant objective data. In this paper, only the form of the product is considered, but in the actual product design process, color is also one of the important design elements. In the following research, the coupling game of product form and color will be our work. By relying on the advantages of game theory in system evolution and balance, we will establish a coupled game model of product form and color to build a product form color-matching system under the target image.

Author Contributions: Conceptualization, J.S. and K.Q.; methodology, K.Q. and X.Z.; validation, W.Y.; data curation, K.Q.; writing-original draft preparation, K.Q. and X.Z.; writing-review and editing, K.Q. and J.S. All authors have read and agreed to the published version of the manuscript.

Funding: The project is sponsored by National Natural Science Foundation of China (51465037), Hongliu Outstanding Talent Development Program of Lanzhou University of Technology (J201406).

Conflicts of Interest: The authors declare no conflict of interest.

\section{References}

1. Kim, W.; Ko, T.; Rhiu, I.; Yun, M.H. Mining affective experience for a kansei design study on a recliner. Appl. Ergon. 2019, 74, 145-153. [CrossRef] [PubMed]

2. Maleki, S.; Amiri Aghdaie, S.F.; Shahin, A.; Ansari, A. Investigating the relationship among the Kansei-based design of chocolate packaging, consumer perception, and willingness to buy. J. Mark. Commun. 2019, 1-20. [CrossRef]

3. Srivastava, N.; Hinton, G.; Krizhevsky, A. Dropout: A Simple Way to Prevent Neural Networks from Overfitting. J. Mach. Learn. Res. 2014, 15, 1929-1958.

4. Wang, Y.; Mo, D.Y.; Tseng, M.M. Mapping customer needs to design parameters in the front end of product design by applying deep learning. CIRP Ann. 2018, 67, 145-148. [CrossRef]

5. Chen, J.; Luo, N.; Liu, Y.; Liu, L.; Zhang, K.; Kolodziej, J. A hybrid intelligence-aided approach to affect-sensitive e-learning. Computing 2016, 98, 215-233. [CrossRef]

6. Kapoor, A.; Burleson, W.; Picard, R.W. Automatic prediction of frustration. Int. J. Hum. Comput. Stud. 2007, 65, 724-736. [CrossRef]

7. Chai, C.; Liao, J.; Zou, N.; Sun, L. A one-to-many conditional generative adversarial network framework for multiple image-to-image translations. Multimed. Tools Appl. 2018, 77, 22339-22366. [CrossRef]

8. Bertola, P.; Teixeira, J.C. Design as a knowledge agent: How design as a knowledge process is embedded into organizations to foster innovation. Design Stud. 2003, 24, 181-194. [CrossRef] 
9. Feng, Y.X.; Lou, S.H.; Wang, X.P.; Zheng, H.; Gao, Y.C.; Wang, Y.; Tan, J.R. Research on Performance-oriented Perceptual Image Evaluation Method for Cus Tomized Products. J. Mech. Eng. 2020, 56, 181-190.

10. Ehrensberger, D.M.; O'Brien, S. Ergonomics of the translation workplace: Potential for cognitive friction. Transl. Spaces 2015, 4, 98-118. [CrossRef]

11. He, C.X. Analysis of Cognitive Friction in Product Design and Use Process. Packag. Eng. 2010, 31, 58-60.

12. Henson, B.; Barnes, C.; Livesey, R.; Childs, T.; Ewart, K. Affective Consumer Requirements: A Case Study of Moisturizer Packaging. Concurr. Eng. 2006, 14, 187-196. [CrossRef]

13. Nagamachi, M. Kansei Engineering: A new ergonomic consumer-oriented technology for product development. Int. J. Ind. Ergon. 1995, 15, 3-11. [CrossRef]

14. Zhang, X.; Yang, M.; Su, J.; Yang, W.; Qiu, K. Research on product color design decision driven by brand image. Color Res. Appl. 2020, 1-15. [CrossRef]

15. Ding, M.; Bai, Z. Product color emotional design adaptive to product shape feature variation. Color Res. Appl. 2019, 44, 811-823. [CrossRef]

16. Köhler, M.; Falk, B.; Schmitt, R. Applying Eye-Tracking in Kansei Engineering Method for Design Evaluations in Product Development. Int. J. Affect. Eng. 2015, 14, 241-251.

17. Zhang, X.X.; Yang, M.G. Color image knowledge model construction based on ontology. Color Res. Appl. 2019, 44, 651-662. [CrossRef]

18. Kristian, P.; Tanel, M.; Andres, K. Considering Emotions in Product Package Design through Combining Conjoint Analysis with Psycho Physiological Measurements. Procedia-Soc. Behav. Sci. 2014, 148, $280-290$.

19. Huang, Y.; Chen, C.H.; Wang, I.H.; Khoo, L.P. A product configuration analysis method for emotional design using a personal construct theory. Int. J. Ind. Ergonom. 2014, 44, 120-130. [CrossRef]

20. Wang, Z.; Liu, W.; Yang, M.; Han, D. A Multi-Objective Evolutionary Algorithm Model for Product Form Design Based on Improved SPEA2. Appl. Sci. 2019, 9, 2944. [CrossRef]

21. Yuan, G.S.; Xie, Q.S.; Pan, W.J. Color design based on Kansei engineering and interactive genetic algorithm. AJME Acad. J. Manuf. Eng. 2017, 15, 12-18.

22. Guo, F.; Li, F.; Nagamachi, M.; Hu, M.; Li, M. Research on color optimization of tricolor product considering color harmony and users' emotion. Color Res. Appl. 2020, 45, 156-171. [CrossRef]

23. Ding, L.; Che, J.M.; Dong, X.F. Product Bionics Form Design Based on Users' Kansei Image. Appl. Mech. Mater. 2010, 37-38, 910-914. [CrossRef]

24. Ho, C.H.; Lu, Y.N. Can pupil size be measured to assess design products? Int. J. Ind. Ergonom. 2014, 44, 436-441. [CrossRef]

25. Jiao, Y.; Qu, Q.X. A proposal for Kansei knowledge extraction method based on natural language processing technology and online product reviews. Comput. Ind. 2019, 108, 1-11. [CrossRef]

26. Chang, Y.M.; Chen, C.W. Kansei assessment of the constituent elements and the overall interrelations in car steering wheel design. Int. J. Ind. Ergonom. 2016, 56, 97-105. [CrossRef]

27. Zhou, L.; Xue, C.Q.; Tang, W.C.; Li, J.; Niu, Y.F. User Perceptual Prediction Model of Product Information Interface. Comput. Integr. Manuf. Syst. 2014, 20, 544-554.

28. Zhu, G.N.; Hu, J.; Qi, J.; Gu, C.C.; Peng, Y.H. An Integrated AHP and VIKOR for Design Concept Evaluation Based on Rough Number. Adv. Eng. Inform. 2015, 29, 408-418. [CrossRef]

29. Quan, H.; Li, S.; Wei, H.; Hu, J. Personalized Product Evaluation Based on GRA-TOPSIS and Kansei Engineering. Symmetry 2019, 11, 867. [CrossRef]

30. Shieh, M.D.; Li, Y.; Yang, C.C. Comparison of multi-objective evolutionary algorithms in hybrid Kansei engineering system for product form design. Adv. Eng. Inform. 2018, 36, 31-42. [CrossRef]

31. Quan, H.; Li, S.; Hu, J. Product Innovation Design Based on Deep Learning and Kansei Engineering. Appl. Sci. 2018, 8, 2397. [CrossRef]

32. Lokman, A.M.; Haron, M.B.; Abidin, S.Z.; Abd Khalid, N.E.; Ishihara, S. Prelude to Natphoric Kansei Engineering Framework. J. Softw. Eng. Appl. 2013, 6, 638-644. [CrossRef]

33. Wang, T.X.; Zhou, M.Y. A method for product form design of integrating interactive genetic algorithm with the interval hesitation time and user satisfaction. Int. J. Ind. Ergonom. 2020, 76, 102901. [CrossRef]

34. Deng, L.; Wang, G.H. Application of EEG and Interactive Evolutionary Design Method in Cultural and Creative Product Design. Comput. Intell. Neurosci. 2019, 1-16. [CrossRef] [PubMed]

35. Li, Y.F.; Shieh, M.D.; Yang, C.C. A Posterior Preference Articulation Approach to Kansei Engineering System for Product Form Design. Res. Eng. Des. 2019, 30, 3-19. [CrossRef] 
36. Javad, K.; Owain, P. A semantic discontinuity detection (SDD) method for comparing designers' product expressions with users' product impressions. Design Stud. 2019, 62, 36-67.

37. Norman, D.A. The Design of Everyday Things; CITIC Press Group: Beijing, China, 2003; pp. 17-18.

38. Yang, Y.P.; Liu, Q. Product form design method driven by design intent. Comput. Integr. Manuf. Syst. 2015, 21, 867-874.

39. Lai, C.; Chen, X.; Chen, X.; Wang, Z.; Wu, X.; Zhao, S. A fuzzy comprehensive evaluation model for flood risk based on the combination weight of game theory. Nat. Hazards 2015, 77, 1243-1259. [CrossRef]

40. Liu, T.; Deng, Y.; Chan, F. Evidential Supplier Selection Based on DEMATEL and Game Theory. Int. J. Fuzzy Syst. 2018, 20, 1321-1333. [CrossRef]

41. Zhou, X.; Deng, X.; Deng, Y.; Mahadevan, S. Dependence assessment in human reliability analysis based on D numbers and AHP. Nucl. Eng. Des. 2017, 313, 243-252. [CrossRef]

42. Su, J.N.; Zhang, X.X.; Jing, N.; Chen, X. Research on the entropy evaluation of product styling image under the cognitive difference. J. Mach. Des. 2016, 33, 105-108.

43. Li, L.H.; Mo, R. Production Task Queue Optimization Based on Multi-Attribute Evaluation for Complex Product Assembly Workshop. PLoS ONE 2015, 10, e0134343. [CrossRef] [PubMed]

44. Zhao, H.; Li, N. Optimal Siting of Charging Stations for Electric Vehicles Based on Fuzzy Delphi and Hybrid Multi-Criteria Decision Making Approaches from an Extended Sustainability Perspective. Energies 2016, 9, 270. [CrossRef]

45. Yang, C.C. A Classification-Based Kansei Engineering System for Modeling Consumers' Affective Responses and Analyzing Product Form Features. Expert Syst. Appl. 2011, 38, 11382-11393. [CrossRef]

46. Wang, L.; Cao, Q.; Mo, X. Study of Users' Kansei on Commercial Aircraft Cockpit Interior Design. J. Mech. Eng. 2014, 50, 122-126. [CrossRef]

47. Liu, G.; Hu, F.; Wang, Y.; Wang, H. Assessment of Lexicographic Minimax Allocations of Blue and Green Water Footprints in the Yangtze River Economic Belt Based on Land, Population, and Economy. Int. J. Environ. Res. Public Health 2019, 16, 643. [CrossRef]

48. Guo, G.; Lin, L.; Xu, N. User-perceived styling experience of smart vehicles: A method to combine eye tracking with semantic differences. IET Intell. Transp. Syst. 2019, 13, 72-78.

49. Chen, M. Research of Design Elements Based on Cognitive Friction. Ph.D. Thesis, Southeast University, Nanjing, China, 6 January 2017.

(C) 2020 by the authors. Licensee MDPI, Basel, Switzerland. This article is an open access article distributed under the terms and conditions of the Creative Commons Attribution (CC BY) license (http://creativecommons.org/licenses/by/4.0/). 